\title{
EDITORIAL
}

\section{Voorwoord bij het themanummer Andrologie}

\author{
Gert R. Dohle ${ }^{1} \cdot$ Marij Dinkelman-Smit $^{1}$
}

Published online: 6 November 2018

(c) The Author(s) 2018

Voor u ligt een speciale uitgave van het Nederlands Tijdschrift voor Urologie over andrologie. De leden van de werkgroep Andrologie van de NVU hebben op verzoek van de redactie overzichtsartikelen geschreven over actuele onderwerpen in de andrologie. Een mooie gelegenheid voor u om weer helemaal op de hoogte te raken van recente andrologische ontwikkelingen.

Ongeveer 10\% van de urologische zorg in Nederland betreft andrologie. Het gaat daarbij vooral om fertiliteit en sterilisatie, mannelijke seksuele disfuncties, hypogonadisme en de ziekte van peyronie. Ook de echografie van het scrotum en de penis is vast onderdeel geworden van de andrologische zorg. Helaas blijft de belangstelling voor andrologie wat achter bij arts-assistenten urologie in opleiding in vergelijking tot uro-oncologie en functionele urologie. Dat is jammer, want de opleidingsmogelijkheden in de andrologie en seksuologie zijn in voldoende mate aanwezig en aantekeningen als subspecialist in deze aandachtsgebieden worden geboden door de European Society of Sexual Medicine (ESSM) en The European Academy of Andrology (EAA).

De huidige trend naar superspecialisatie en centralisatie van medisch zorg is ook aan de andrologie niet voorbijgegaan: in de zeven onderwijs- en opleidingsregio's (OOR's) van Nederland is ten minste één centrum voor andrologische zorg aanwezig. Deze centra richten zich vooral op superspecialistische zorg, zoals IVF/ICSI met chirurgisch verkregen zaadcellen, de behandeling van patiënten met het Klinefelter-syndroom, van mannen met hypogonadisme, de implantatie van de erectieprothese en de behandeling van peniele kromstand. Het andrologiecentrum van het Amsterdam UMC, locatie VUmc, richt zich ook nog op de zorg voor transgenderpatiënten. Het streven is om in al deze centra een gecertificeerd uroloog-androloog te positioneren, voor zover dit nog niet is gerealiseerd.

Toch blijft er nog voldoende andrologische zorg over voor de algemene urologische praktijk, zoals de diagnostiek en behandeling van mannelijke seksuele disfuncties, scrotale pathologie (inclusief echografie), testosterontekort, circumcisies en sterilisaties, varicocelebehandeling en scrotale operaties. Het is dus ook voor de algemene uroloog van belang om hun andrologische kennis (en vaardigheden) op niveau te houden. Zij moeten immers voorlichting kunnen geven en doelgericht kunnen verwijzen naar het regionale andrologiecentrum.

Veel leesplezier

Gert Dohle

Marij Dinkelman-Smit

Open Access This article is distributed under the terms of the Creative Commons Attribution 4.0 International License (http:// creativecommons.org/licenses/by/4.0/), which permits unrestricted use, distribution, and reproduction in any medium, provided you give appropriate credit to the original author(s) and the source, provide a link to the Creative Commons license, and indicate if changes were made.

Gert R. Dohle uroloog, hoofd sector Andrologie

Marij Dinkelman-Smit EAA-gecertificeerd klinisch androloog
Gert R. Dohle, MD, PhD

g.r.dohle@erasmusmc.nl

1 Sector Andrologie, afdeling Urologie, ErasmusMC, Rotterdam, Nederland 